\title{
The effects of competitive interactions on variances and on seed germination in spring barley (Hordeum vulgare)
}

\author{
P. D. S. Caligari* and W. Powell
}

Scottish Crop Research Institute, Pentlandfield, Roslin, Midlothian, EH25 9RF Scotland.

Competition in spring barley is shown to affect between plant variation and hence the observed heritability of characters. It is also shown that seed germination can be affected by the competitive interactions experienced by the parents. Both of these features point to the complications of attempting early-generation selection in barley breeding programmes as well as with many other crop species.

\section{INTRODUCTION}

The experimental and analytical methods déveloped by Mather and Caligari (1981, 1983) have been applied to six genotypes of spring barley in order to investigate the role of intergenotypic competition in the selection process for a number of characters of economic importance (Powell, Caligari, Goudappel and Thomas, 1986). Significant levels of intergenotypic competition were detected and such complicating factors can be expected to introduce bias during early-generation selection procedures. These analyses were based on mean performance. The present paper focuses attention on the effects of competitive interactions on the between plant variances for the same characters. Furthermore, the possible "carry over" effects of competition on germination in a subsequent generation are considered.

\section{MATERIALS AND METHODS}

The genotypes investigated and the experimental design employed are described in detail by Powell et al. (1986) and only a brief description is given here. The genotypes were derived by single seed descent from two crosses (Brim, 1966). Three lines (coded A, B and C) were sampled from the cross BH4/143/2 $\times$ Ark Royal and three (D, E and F) from Heriot $\times$ Rif.

The experimental design employed was as described by Mather and Caligari (1981) and in-

* Present address: Department of Agricultural Botany, The University of Reading, Whiteknights, Reading, RG6 2AS, U.K. volved growing each genotype in a series of monocultures and in duocultures with various frequencies of each component, but maintaining a total number $N$ (in this case 60) plants in each plot giving a modified substitution experiment. The structure of the experiment may be illustrated by reference to genotype A:

Number of plants per plot

Monoculture A: 1015

$\begin{array}{llll}\text { Duoculture A:B } & 15: 45 & 30: 30 & 45: 15\end{array}$

Duoculture A:D $\quad 15: 45 \quad 30: 30 \quad 45: 15$ 60

As shown above, it was practicable to grow only two combinations of duoculture for each of the six primary genotypes, but the combination of $A$ with $B$ can be regarded as one with $A$ as the primary genotype as well as one with $B$ as primary. Thus the combinations were:

$$
\mathrm{A}: \mathrm{B}, \mathrm{A}: \mathrm{D}, \mathrm{B}: \mathrm{C}, \mathrm{C}: \mathrm{F}, \mathrm{D}: \mathrm{E} \text { and } \mathrm{E}: \mathrm{F}
$$

The experiment was set up as a randomised complete block of two replicates. Each replicate consisted of 48 plots. A maximum of 60 seeds per plot was sown by hand at a density of 388 plants per square metre in the field at the Murrays Farm, East Lothian, in 1984. The experiment was netted to prevent bird damage and the perimeter was sown with the cultivar Tweed to reduce edge effects. The experiment was sprayed with a broad spectrum fungicide to prevent disease development.

After harvest the following characters were scored: the weight of grain on the main stem in $g$ (MSW), final plant height in $\mathrm{cm}(\mathrm{Ht})$, number of 
grains on the main stem (GN), thousand grain weight (TGW), number of fertile tillers per plant (TN) and the total yield of grain per plant in $g$ (SPY). The germination of the seed produced was assessed 11 months after harvest by placing 100 seeds of each genotype from each plot on moist filter paper in a petri-dish at $20 \pm 2^{\circ} \mathrm{C}$. After five days the number of seeds that had germinated were counted, giving the percentage germination which was converted into angles.

\section{RESULTS AND ANALYSES}

The results from all the plants of the same genotype within a plot were used to obtain the variance between plants. The square roots of such variances were analysed using the methods proposed by Mather and Caligari (1981). The model, assuming a linear relationship between the square root of the variance for a character and the number of plants per plot, was fitted for the 7 characters. Only one of the characters, GN, showed any evidence of non-linearity in that the residual variation around the fitted line was significantly greater than the replicate error variance at the 5 per cent probability level. As this was the only character which showed a departure from lineariîy and, moreover it was only just formally significant, it was taken that the linear relationships were adequate. From the estimates of the regression slopes for monocul- tures and duoculture, the intra- and intergenotypic competition effects ( $c$ values) were obtained (Mather, Hill and Caligari, 1982) and are given in table 1. From these values, following Mather and Caligari (1983), estimates of $\bar{c}$ (the overall competitive effect), $r$ (the response), $a$ (the aggression) and $i$ (the interaction) were obtained for the six pairs of genotypes as described by Powell et al. (1986), and are presented in table 2.

Two of the characters, MSW and $\mathrm{Ht}$, have significant $i$ effects for some of the pairs and indicate that a multiplicative model, rather than the additive one used to estimate $r$ and $a$, might have been more appropriate. Nevertheless, the results indicate that competition is having an effect. With TN there is clear evidence that competition is present in 4 of the 6 pairs of genotypes, with genotype $\mathrm{C}$ differing in response from the other genotypes. The other 3 characters, namely $\mathrm{GN}$, TGW and SPY, give evidence of competition having an effect but with no particular pattern of aggression or response between the genotypes. It should be noted that in table 1 some of the intragenotypic competition effects are negative, which could be taken as indicative of "auto-facilitation", but only one ( $c_{\mathrm{AA}}$ for $\mathrm{Ht}$ ) is significant. Also in table 2 some of the $\bar{c}$ values are negative and significant, again this would suggest facilitation if the mean expression of the characters was being considered. However, in the present case the negative $\bar{c}$ values indicate that the variances (or

Table 1 Estimates of the intra- and intergenotypic competition effects based on the square root of the variances for six agronomic characters

\begin{tabular}{|c|c|c|c|c|c|c|}
\hline & $\begin{array}{l}\text { MSW } \\
\left(\times 10^{3}\right)\end{array}$ & $\begin{array}{l}\mathrm{Ht} \\
\left(\times 10^{2}\right)\end{array}$ & $\begin{array}{l}\text { TN } \\
\left(\times 10^{2}\right)\end{array}$ & $\begin{array}{l}\mathrm{GN} \\
\left(\times 10^{2}\right)\end{array}$ & $\begin{array}{l}\text { TGW } \\
\left(\times 10^{2}\right)\end{array}$ & $\begin{array}{l}\text { SPY } \\
\left(\times 10^{2}\right)\end{array}$ \\
\hline$c_{A \mathcal{A}}$ & $-0 \cdot 80$ & $-5 \cdot 16^{*}$ & $3 \cdot 79$ & 0.54 & $-0 \cdot 33$ & $4 \cdot 45$ \\
\hline$c_{A B}$ & $-3 \cdot 19^{* *}$ &,$-12 \cdot 90^{* * *}$ & 2.99 & $-4 \cdot 38$ & $-9 \cdot 71^{* * *}$ & $4 \cdot 03$ \\
\hline$c_{A D}$ & $-4 \cdot 00^{* * *}$ & $-6 \cdot 72^{*}$ & 1.98 & $-9 \cdot 53^{* * *}$ & $-3 \cdot 47$ & 1.96 \\
\hline$c_{B B}$ & $0 \cdot 29$ & -1.93 & $-1 \cdot 17$ & $-2 \cdot 58$ & $-4 \cdot 16$ & $2 \cdot 12$ \\
\hline$c_{B A}$ & $-1 \cdot 32$ & $-12 \cdot 19 * *$ & $7 \cdot 01 *$ & $-1 \cdot 70$ & $-4 \cdot 24$ & $5 \cdot 86^{*}$ \\
\hline$c_{B C}$ & $-2.79 * *$ & $-8 \cdot 24^{*}$ & 3.99 & -3.90 & $-10 \cdot 47^{* * *}$ & 0.94 \\
\hline$c_{C C}$ & -1.43 & 1.99 & $13 \cdot 14^{*}$ & $-3 \cdot 71$ & $-2 \cdot 54$ & $8 \cdot 78^{* *}$ \\
\hline$c_{C B}$ & $-2 \cdot 48^{*}$ & $-3 \cdot 22$ & $9 \cdot 12$ & $-14 \cdot 17^{* * *}$ & $-6 \cdot 00^{*}$ & $9 \cdot 68^{* *}$ \\
\hline$c_{C F}$ & $-3 \cdot 31^{* * *}$ & $-6 \cdot 59^{*}$ & $15 \cdot 83^{*}$ & $-5 \cdot 46^{*}$ & $-8 \cdot 38^{* *}$ & $11 \cdot 81^{* * *}$ \\
\hline$c_{D D}$ & -0.94 & 3.53 & $8 \cdot 58^{*}$ & $-1 \cdot 76$ & $-5 \cdot 21$ & $8 \cdot 07^{* *}$ \\
\hline$c_{D A}$ & $-1 \cdot 89^{* *}$ & $-4 \cdot 79$ & -0.93 & $-1 \cdot 06$ & $-5 \cdot 70$ & $1 \cdot 23$ \\
\hline$c_{D E}$ & $1 \cdot 55$ & $-4 \cdot 48$ & $-2 \cdot 47$ & $0 \cdot 37$ & $0 \cdot 13$ & $11 \cdot 78$ \\
\hline$c_{E E}$ & $-0 \cdot 28$ & $-3 \cdot 27$ & $4 \cdot 85^{*}$ & $-2 \cdot 06$ & $-0 \cdot 80$ & $6 \cdot 50^{* *}$ \\
\hline$c_{E D}$ & 0.49 & $7 \cdot 29 *$ & $6 \cdot 27^{*}$ & $1 \cdot 38$ & 0.72 & $6 \cdot 54^{* *}$ \\
\hline$c_{E F}$ & $-1 \cdot 16$ & $-14 \cdot 97^{* *}$ & $4 \cdot 58$ & $-2 \cdot 05$ & $-1 \cdot 1 \delta$ & $4 \cdot 05$ \\
\hline$c_{F F}$ & $-0 \cdot 72$ & $-4 \cdot 64$ & $6 \cdot 44^{*}$ & $-2 \cdot 70$ & -0.74 & $8 \cdot 71^{* *}$ \\
\hline$c_{F C}$ & -0.04 & $-3 \cdot 61$ & $3 \cdot 78$ & $-1 \cdot 10$ & $0 \cdot 14$ & $6 \cdot 04^{*}$ \\
\hline$c_{F E}$ & -0.87 & $-4 \cdot 64$ & -0.19 & $-1 \cdot 50$ & $-2 \cdot 28$ & 1.49 \\
\hline
\end{tabular}

* $\mathrm{P}=0.05-0.01,{ }^{* *} \mathrm{P}=0.01-0.001, * * * \mathrm{P}=<0.001$ 
Table 2 Estimates of the mean competitive value $(\bar{c})$, the difference in response $(r)$ between genotypes, the difference in aggression $(a)$ and the interaction $(i)$ between $r$ and $a$ for the variances of the characters in each of the six combinations

\begin{tabular}{|c|c|c|c|c|c|c|c|}
\hline & & $\begin{array}{l}\text { MSW } \\
\left(\times 10^{3}\right)\end{array}$ & $\begin{array}{l}\mathrm{Ht} \\
\left(\times 10^{2}\right)\end{array}$ & $\begin{array}{l}\text { TN } \\
\left(\times 10^{2}\right)\end{array}$ & $\begin{array}{l}\text { GN } \\
\left(\times 10^{2}\right)\end{array}$ & $\begin{array}{l}\text { TGW } \\
\left(\times 10^{2}\right)\end{array}$ & $\begin{array}{l}\text { SPY } \\
\left(\times 10^{2}\right)\end{array}$ \\
\hline A/B & $\begin{array}{l}\bar{c} \\
r \\
a \\
i\end{array}$ & $\begin{array}{c}-1 \cdot 25^{* *} \\
-0.74 \\
0.19 \\
1.00\end{array}$ & $\begin{array}{l}-8.04^{* * *} \\
-1.00 \\
-0.63 \\
4.50^{* *}\end{array}$ & $\begin{array}{r}3 \cdot 15 \\
0 \cdot 23 \\
2 \cdot 24 \\
-1 \cdot 84\end{array}$ & $\begin{array}{r}-2 \cdot 03 \\
0 \cdot 11 \\
1.45 \\
1.01\end{array}$ & $\begin{array}{l}-4 \cdot 61^{* * * *} \\
-0 \cdot 41 \\
2 \cdot 32 \\
2 \cdot 36\end{array}$ & $\begin{array}{c}4 \cdot 12^{* *} \\
0 \cdot 12 \\
1.04 \\
-0.83\end{array}$ \\
\hline A/D & $\begin{array}{l}\bar{c} \\
r \\
a \\
i\end{array}$ & $\begin{array}{c}-1.91^{* *} \\
-0.49 \\
0.56 \\
1.04\end{array}$ & $\begin{array}{c}-3 \cdot 29 * \\
-2.65 \\
-1.69 \\
2.47\end{array}$ & $\begin{array}{r}3.35 \\
-0.47 \\
-1.92 \\
2.83\end{array}$ & $\begin{array}{r}-2.95 \\
-1.54 \\
2.69 \\
2.34\end{array}$ & $\begin{array}{c}-3.68^{* *} \\
1.78 \\
0.66 \\
0.91\end{array}$ & $\begin{array}{c}3.93^{*} \\
-0.72 \\
-1.09 \\
2.33\end{array}$ \\
\hline $\mathrm{B} / \mathrm{C}$ & $\begin{array}{l}\bar{c} \\
r \\
a \\
i\end{array}$ & $\begin{array}{c}-1.60^{* * *} \\
0.35 \\
0.51 \\
1.03^{*}\end{array}$ & $\begin{array}{c}-2 \cdot 85^{*} \\
-2 \cdot 23 \\
2 \cdot 75 \\
2 \cdot 88^{*}\end{array}$ & $\begin{aligned} & 6 \cdot 27^{* * *} \\
&- 4 \cdot 86^{*} \\
&-2 \cdot 29 \\
&-0 \cdot 28\end{aligned}$ & $\begin{array}{c}-6 \cdot 09^{* * *} \\
2 \cdot 85 \\
-2 \cdot 28 \\
2 \cdot 94\end{array}$ & $\begin{array}{l}-5 \cdot 79^{* * *} \\
-1 \cdot 52 \\
0 \cdot 71 \\
2 \cdot 44\end{array}$ & $\begin{array}{c}5 \cdot 38^{* * *} \\
-3.85^{*} \\
0.52 \\
0.07\end{array}$ \\
\hline$C / F$ & $\begin{array}{l}\bar{c} \\
r \\
a \\
i\end{array}$ & $\begin{array}{c}-1 \cdot 37^{* *} \\
-1 \cdot 00^{*} \\
0.64 \\
0.30\end{array}$ & $\begin{array}{c}-3 \cdot 21^{*} \\
0.91 \\
2 \cdot 40 \\
1 \cdot 89\end{array}$ & $\begin{array}{c}9 \cdot 80^{* * *} \\
4 \cdot 69^{*} \\
-1 \cdot 34 \\
-0 \cdot 01\end{array}$ & $\begin{array}{r}-3 \cdot 24 \\
-1 \cdot 34 \\
0.84 \\
0.04\end{array}$ & $\begin{array}{c}-2 \cdot 88^{*} \\
-2 \cdot 58^{*} \\
1.68 \\
1 \cdot 24\end{array}$ & $\begin{array}{c}8.84^{* * *} \\
1.46 \\
-1.43 \\
0.09\end{array}$ \\
\hline$D / E$ & $\begin{array}{l}\bar{c} \\
r \\
a \\
i\end{array}$ & $\begin{array}{r}0.21 \\
0.10 \\
-0.43 \\
-0.81\end{array}$ & $\begin{array}{c}0.77 \\
-1.24 \\
4.64^{* *} \\
-0.64\end{array}$ & $\begin{array}{c}4 \cdot 31^{*} \\
-1 \cdot 25 \\
3 \cdot 12 \\
2 \cdot 41\end{array}$ & $\begin{array}{r}-0.52 \\
-0.02 \\
0.33 \\
-1.39\end{array}$ & $\begin{array}{l}-1 \cdot 00 \\
-0.95 \\
-1.25 \\
-2.01\end{array}$ & $\begin{array}{l}8 \cdot 22 * * * \\
1.70 \\
-0.92 \\
-0.94\end{array}$ \\
\hline $\mathrm{E} / \mathrm{F}$ & $\begin{array}{l}\bar{c} \\
r \\
a \\
i\end{array}$ & $\begin{array}{r}-0.76 \\
0.04 \\
0.18 \\
0.26\end{array}$ & $\begin{array}{l}-4 \cdot 88^{* * *} \\
-4 \cdot 24^{* *} \\
-4 \cdot 92^{* * *} \\
-0.93\end{array}$ & $\begin{array}{c}3.92^{*} \\
0.79 \\
-1.59 \\
1.72\end{array}$ & $\begin{array}{r}-2.08 \\
0.02 \\
0.30 \\
-0.30\end{array}$ & $\begin{array}{r}-1 \cdot 25 \\
0.26 \\
-0.29 \\
0.48\end{array}$ & $\begin{array}{c}5 \cdot 19^{* * *} \\
0.09 \\
-1 \cdot 19 \\
2 \cdot 42\end{array}$ \\
\hline
\end{tabular}

* $\mathrm{P}=0.05-0.01, * * \mathrm{P}=0.01-0.001, * * * \mathrm{P}=<0.001$

more strictly the square roots of the variances) are increasing with increasing competition, i.e., as competition increases so the phenotypic expression of a given genotype becomes more variable.

The same analysis was carried out for the percent mean germination (transformed to angles) and the competitive values are presented in table 3 , while the $\bar{c}, r, a$ and $i$ values are given in table 4. There are fewer significant estimates for percent germination than for the within family variances but they show that genotype $F$ responds differently from the other 5 genotypes to the effects of compe-

Table 3 Estimates of the intra and intergenotypic competitive effects for percent germination (in angles)

\begin{tabular}{lll}
\hline$c_{A A}=0.055$ & $c_{B B}=0.129$ & $c_{C C}=0.054$ \\
$c_{A B}=-0.055$ & $c_{B A}=-0.061$ & $c_{C B}=-0.035$ \\
$c_{A D}=-0.016$ & $c_{B C}=0.143$ & $c_{C F}=0.002$ \\
$c_{D D}=0.046$ & $c_{E E}=-0.053$ & $c_{F F}=-0.196^{* * *}$ \\
$c_{D A}=-0.024$ & $c_{E D}=0.035$ & $c_{F C}=-0.109$ \\
$c_{D E}=0.028$ & $c_{E F}=0.022$ & $c_{F E}=-0.175^{* *}$ \\
\hline
\end{tabular}

** $\mathrm{P}=0.01-0.001, * * * \mathrm{P}=<0.001$ tition. Interestingly, the only significant $\bar{c}$ value is negative and thus points to genotype $F$ showing increased germination with increasing competition, i.e., facilitation. Thus the next generation shows the effects of competitive interactions experienced by the parents. Germination was not measured under field conditions but assuming that similar effects would occur it is likely that other aspects of plant phenotype would be subsequently affected (Harper 1977).

Table 4 Estimates for percent germination (in angles) of the mean competitive value $(\bar{c})$, the differences in response $(r)$ between genotypes, the difference in aggression $(a)$ and the interaction ( $i$ ) between $r$ and $a$ for each of the six combinations

\begin{tabular}{|c|c|c|c|c|c|}
\hline A/B & $\begin{aligned} \bar{c} & =0.017 \\
r & =-0.017 \\
a & =-0.020 \\
i & =0.075\end{aligned}$ & $\mathrm{~A} / \mathrm{D}$ & $\begin{aligned} \vec{c} & =0.015 \\
r & =0.004 \\
a & =0.000 \\
i & =0.035\end{aligned}$ & $\mathrm{~B} / \mathrm{C}$ & $\begin{aligned} \bar{c} & =0.073 \\
r & =0.063 \\
a & =-0.025 \\
i & =0.019\end{aligned}$ \\
\hline $\mathrm{C} / \mathrm{F}$ & $\begin{aligned} \bar{c} & =-0.062 \\
r & =0.090^{*} \\
a & =0.035 \\
i & =0.009\end{aligned}$ & $\mathrm{D} / \mathrm{E}$ & $\begin{aligned} \bar{c} & =0.014 \\
r & =0.023 \\
a & =0.027 \\
i & =-0.017\end{aligned}$ & $\mathrm{E} / \mathrm{F}$ & $\begin{aligned} \bar{c} & =-0.101^{*} \\
r & =0.085^{*} \\
a & =-0.014 \\
i & =-0.024\end{aligned}$ \\
\hline
\end{tabular}

$* \mathrm{P}=0.05-0.01$ 


\section{DISCUSSION AND CONCLUSIONS}

The separation of the effects of intra- and intergenotypic competition allows the relative magnitude of intergenotypic competition to be assessed. Such analyses based on mean performance (Powell et al., 1986) have indicated the presence of significant levels of intergenotypic competition in barley. Consequently selection for monoculture performance under conditions which display intergenotypic competition may result in a bias being introduced. The present study using the same material demonstrates that competition between genotypes of barley can also affect second degree statistics, i.e., the between plant variances. Thus estimates of heritability and hence the efficiency of selection will vary depending on the competitive pressure exerted by individuals within a population. These two features of intergenotypic competition obviously complicate and confound methods used for early-generation selection in many crop species.

The effect of competition on characters in subsequent generations has also been investigated. Seed germination in this experiment was affected by the competitive pressure experienced by the parental genotypes. Such an effect will have profound implications for many characters since differential germination can influence establishment and survival. As stated by Harper (1977), "The advantage which an early emerging seedling gains is far greater than can be accounted for merely by the greater time that it has been allowed to grow".

The results presented here reinforce the general theme that early-generation selection should be avoided in barley breeding programmes. Intergenotypic competition has previously been shown to affect the means of agronomic characters in spring barley (Powell et al., 1986) In the present paper the variances of such characters are also shown to be affected and, in addition, it has been demonstrated that seed germination can be influenced by the competitive pressures experienced by the parents. Thus it is clear that if selection is practiced in early generations when genotypes are present in heterogeneous mixtures its effects will be confounded with the effects of competition in its broadest sense. This argument may be extended to other crop species where the procedures of early-generation selection are practiced.

Acknowledgements We thank Messrs W. Wood, G. Young, P. Degreef, P. Goudappel and Mrs J. I. Gordon for technical assistance and Dr W. T. B. Thomas for providing some of the computing.

\section{REFERENCES}

BRIM, C. A. 1966. A modified pedigree method of selection in soya beans. Crop Sci., 6, 220.

HARPER, J. L. 1977. Population Biology of Plants, Academic Press, London, pp 165-166.

MATHER, K. AND CALIGARI, P. D. S. 1981. Competitive interactions in Drosophila melanogaster II Measurement of competition. Heredity, 46, 239-254.

MATHER, K. AND CAligARI, P. D. S. 1983. Pressure and response in competitive interactions. Heredity, 51, 435-454.

MATHER, K., HILL, J. AND CALIGARI, P. D. S. 1982. Analysis of competitive ability among genotypes of perennial ryegrass. Heredity, 48, 421-434.

POWELL, W., CALIGARI, P. D. S., GOUDAPPEL, P. H. AND THOMAS, W. T. B. 1986. Competitive effects in monocultures and mixtures of spring barley (Hordeum vulgare). Theor. Appl. Genet, 71, 443-450. 